\title{
The results of raster scan laser conditioning studies on DKDP triplers using Nd:YAG and excimer lasers
}

Mike Runkel, Kurt Neeb, Mike Staggs, Jerome Auerbach, Alan Burnham

This article was submitted to

Laser-Induced Damage in Optical Materials, Nov. 1-2, 2001 Boulder, CO.

Lawrence

Livermore

National

Laboratory

November 1-2, 2001 


\section{DISCLAIMER}

This document was prepared as an account of work sponsored by an agency of the United States Government. Neither the United States Government nor the University of California nor any of their employees, makes any warranty, express or implied, or assumes any legal liability or responsibility for the accuracy, completeness, or usefulness of any information, apparatus, product, or process disclosed, or represents that its use would not infringe privately owned rights. Reference herein to any specific commercial product, process, or service by trade name, trademark, manufacturer, or otherwise, does not necessarily constitute or imply its endorsement, recommendation, or favoring by the United States Government or the University of California. The views and opinions of authors expressed herein do not necessarily state or reflect those of the United States Government or the University of California, and shall not be used for advertising or product endorsement purposes.

This is a preprint of a paper intended for publication in a journal or proceedings. Since changes may be made before publication, this preprint is made available with the understanding that it will not be cited or reproduced without the permission of the author.

This report has been reproduced directly from the best available copy.

Available to DOE and DOE contractors from the Office of Scientific and Technical Information

P.O. Box 62, Oak Ridge, TN 37831

Prices available from (423) 576-8401 http:/ /apollo.osti.gov/bridge/

Available to the public from the National Technical Information Service

U.S. Department of Commerce 5285 Port Royal Rd., Springfield, VA 22161

http://www.ntis.gov/

\section{OR}

Lawrence Livermore National Laboratory

Technical Information Department's Digital Library

http://www.llnl.gov/tid/Library.html 


\title{
The results of raster-scan laser conditioning studies on DKDP triplers using Nd:YAG and excimer lasers
}

\author{
Mike Runkel*, Kurt Neeb*, Mike Staggs, Jerome Auerbach, Alan Burnham \\ Lawrence Livermore National Laboratory, P.O. Box 808, L-250, Livermore, CA 94550 \\ Phone: (925)-424-2210, runkel1@1lnl.gov
}

\begin{abstract}
In this paper we present the results of damage tests performed at 1064 and 355-nm at 8-10 ns on conventional and rapid growth DKDP tripler crystals. The crystals were laser conditioned prior to damage testing by raster scanning using either Nd:YAG (1064 and $355 \mathrm{~nm}, 8-10 \mathrm{~ns}$ ) or excimer lasers at 248, 308 or $351 \mathrm{~nm}$ with pulse durations of approximately 30-47 $\mathrm{ns}$. The results show that it is possible to attain increases in 355-nm damage probability fluences of $2 \mathrm{X}$ for excimer conditioning at 248 and $308 \mathrm{~nm}$. However these wavelengths can induce absorption sufficient to induce bulk fracture by thermal shock when impurities such as arsenic, rubidium and sulfur are present in the crystals in sufficient quantity. Tests to evaluate the efficiency of 351-nm conditioning (XeF excimer) show improvements of $2 \mathrm{X}$ and that thermal fracture by induced absorption is not a problem. We also discuss our recent discovery that low fluence raster scanning at UV wavelengths leads to 1064-nm damage thresholds of over $100 \mathrm{~J} / \mathrm{cm}^{2}$ (10-ns pulses).
\end{abstract}

Keywords: KDP, DKDP, laser damage, laser conditioning, excimer lasers, induced absorption

\section{INTRODUCTION}

Over the past five years substantial effort has been placed on developing large (50-cm) KDP and DKDP crystals for Pockels cell and frequency conversion applications on large inertial confinement fusion (ICF) lasers such as the National Ignition Facility (NIF), and Laser Megajoule (LMJ). The development effort has centered on reducing the level of impurity contamination in the starting salts and growth solutions. The effect of these efforts on laser damage performance has been documented in several publications. ${ }^{1-3}$ We have also determined that growth temperature is an important factor influencing damage performance ${ }^{4}$, with crystals grown at lower temperatures achieving higher damage resistance but also being more susceptible to surface crazing and deuterium fractionation. The latter two effects make it difficult to take advantage of low temperature crystals growth for high peak power lasers. Despite the dramatic progress we have made on increasing the damage resistance via growth parameters, our calculations ${ }^{5,6}$ have shown that all suitable material exposed immediately to 8 $\mathrm{J} / \mathrm{cm}^{2}$ average at $351-\mathrm{nm}(3 \mathrm{~ns})$ has unacceptably high bulk damage ( $>0.1 \%$ scattering). As indicated by the results of this paper, post-growth processing by laser raster scanning can greatly reduce bulk damage for $8 \mathrm{~J} / \mathrm{cm}^{2}$ operation.

Laser conditioning is the increase in damage resistance by irradiation of the sample at sub-damage threshold fluences. It has long been known to increase the damage resistance of many laser optical materials. In particular, for KDP and DKDP, damage measurements have shown that the typical degree of conditioning is approximately $2 \mathrm{X}$ at both $1064(1 \omega)$ and 355 $(3 \omega) \mathrm{nm}^{7}$. This degree of conditioning will allow $8 \mathrm{~J} / \mathrm{cm}^{2}$ operation of the high peak power ICF lasers without exceeding the damage obscuration specification for the crystals. In an earlier work ${ }^{8}$, we showed that substantial conditioning would occur on-line, in a scenario such as beamline activation, but this was not optimal because the optic would not typically receive uniform conditioning. It is much more desirable to deliver a uniformly, optimally conditioned optic that is processed off-line to such lasers. Several approaches were considered and rejected as either being too expensive or ineffective. In the end, it appeared that the best approach would be to condition using laser raster scanning, a technique that has been successfully applied to thin film optical coatings. ${ }^{9}$ To that end, we have explored and report here a number of possible scanning scenarios using Nd:YAG and excimer lasers. Specifically, we have examined the effects of $1 \omega$ scanning on $3 \omega$ damage, $3 \omega$ scanning on $1 \omega$ damage and UV scanning on $3 \omega$ damage using tripled $\mathrm{Nd}$ :YAG and $\mathrm{KrF}(248 \mathrm{~nm}), \mathrm{XeCl}(308$ $\mathrm{nm})$ and $\mathrm{XeF}(351-\mathrm{nm})$ excimer lasers.

\footnotetext{
* Current affiliation: Coherent Technologies, 655 Aspen Ridge, Lafayette, CO 80026

*Correspondence: Email: runkel1@1lnl.gov; Telephone: 925-424-2210; Fax: 925-422-3361
} 


\section{DAMAGE AND RASTER SCAN TEST PROCEDURES}

\subsection{Damage Test Facility}

To determine the change in damage resistance due to raster scanning, we performed fixed fluence damage probability tests on the samples. This test, also known as the $\mathrm{S} / 1$ test (single fluence per site), consists of exposing a minimum of ten test sites to a single fluence level for up to 150 shots. The damage probability at that fluence is the percentage of sites that show damage. The fluence is changed in order to map out the damage probability curve from 0 to $100 \%$. This usually requires exposing a total of 40-80 test sites. The measurement precision of the test including both fluence fluctuations and sampling statistics ${ }^{10}$ is $\pm 15 \%$. The data is usually displayed as a plot of damage probability vs. peak fluence and exhibits a characteristic S-shape to which either log-normal or Weibull statistics may be applied. ${ }^{11,12}$.

The Zeus KDP damage test facility at Lawrence Livermore National Laboratory (LLNL) was used to perform all S/1 test measurements reported here. The system consists of a Q-switched Nd:YAG laser operating at $10 \mathrm{~Hz}$. For 1064-nm operation, the beam diameter on the sample was $1.2 \mathrm{~mm}\left(\mathrm{FW} @ 1 / \mathrm{e}^{2}\right)$ and was capable of delivering a maximum fluence of approximately $120 \mathrm{~J} / \mathrm{cm}^{2}$ in a 10-ns pulse (FWHM). For 355-nm operation, the beam diameter was approximately $750 \mu \mathrm{m}$


raster scanning at $1 \omega$ the beam diameter was the same as for damage testing, while for $3 \omega$ scanning it was increased to $\sim 1.5$ $\mathrm{mm}$.

Damage was detected on-line using a 25-mW HeNe laser with beam diameter of $1.5 \mathrm{~mm}$ (FW@1/ $\mathrm{e}^{2}$ ) that was co-linear with the damage beam. Light scattered from bulk damage events at $\sim 45$ degrees was detected with a photomultiplier tube with output to a computer controlled data acquisition system. Backscattered light at $\sim 135$ degrees was observed using a color CCD camera and macro attachment with output to a video monitor for operator determination of damage. Correlation between the two diagnostics was greater than $98 \%$. The sample position in the beam could be controlled by XY stages with $\mu \mathrm{m}$ precision.

Excimer raster scans were performed in the applications laboratory of Microlas/Lambda Physik, Goettingen, Germany. An LPX300i was used for XeCl scanning at $308 \mathrm{~nm}$ while a LPX315i was used for $\mathrm{KrF}$ and XeF scanning at 248 and 351-nm respectively. The scan beams were rectangular shaped using two beam-homogenizers and focus lenses and were gaussian in the short axis and nearly top-hat in the long axis. The optical system was designed to produce peak fluences on the order of $50 \mathrm{~J} / \mathrm{cm}^{2}$ in the sample plane. The pulse duration for the $\mathrm{XeCl}$ was two-humped and when numerically integrated yielded an equivalent square-pulse duration of $46 \mathrm{~ns}$. The FWHM XeCl beam dimensions were $0.3 \mathrm{~mm}$ in the short, gaussian axis by $2.2 \mathrm{~mm}$ for the long axis. The pulse form for the XeF laser was near gaussian with a FWHM value of $30 \mathrm{~ns}$ and its beam dimensions at the sample were $0.2 \mathrm{~mm}$ by $1.56 \mathrm{~mm}$. The pulse duration of the $\mathrm{KrF}$ beam was $30 \mathrm{~ns}$ and its FWHM beam dimensions were $0.55 \mathrm{~mm}$ by $2.1 \mathrm{~mm}$.

\subsection{Raster-scan procedure}

Samples were scanned through the conditioning beam with fixed velocity in the X-direction. At the end of a scan line, the sample was shifted a fixed increment in the Y-direction and scanned in the -X-direction. Laser conditioning was attained using the leading edge of the conditioning beam as shown in Figure 1. For $1 \omega$ and $3 \omega$ Nd:YAG beams, the spatial profile was circular gaussian while for the excimer scans the beam was gaussian in the short axis and approximately top-hat in the long axis. The laser parameters varied in the scans included laser wavelength, pulse duration, peak fluence, laser rep rate, number of scans and scan velocity.

The fill factor, or number of shots-per-site, used in the various scans was determined from the $90 \%$-of-peak-fluence beam diameter $\left(0.9 \mathrm{~F}_{\text {peak }}\right)$ for $\mathrm{Nd}$ :YAG beams and the FW@ $1 / \mathrm{e}^{2}$ width for shaped excimer beams. It is equal to the ratio of beam diameter to the step size per shot. Once the beam profile was known and the fill factor chosen, the stage velocity was set based on the pulse repetition frequency of the laser. 

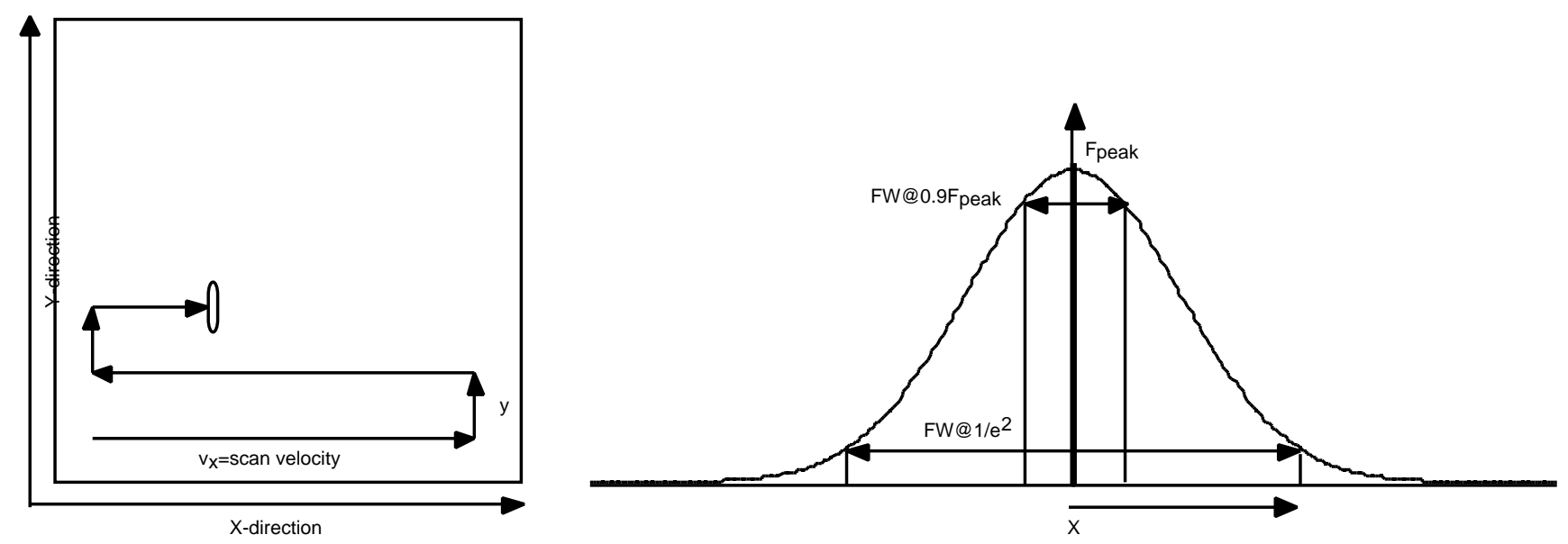

Figure 1. Schematic of raster-scanning on a crystal and the nomenclature used to determine the shots/site fill factor for round $\mathrm{Nd}$ :YAG beams and rectangular-gaussian excimer beams.

\section{TEST SAMPLES}

Most of the samples used in the tests described in this paper were taken from two rapid-growth and two conventional-growth boules. The rapid-growth boules were known as CD35 and BD8. They were two of our earliest large rapid growth boules, but do not currently represent the state-of-the-art in rapid DKDP crystal growth. This material has found extensive use in damage testing mainly because it was available while better material was being grown.

Of the two conventional-growth boules, LL6 was a boule grown for the Beamlet laser in the early 1990s. It contained parts per million levels of arsenic, rubidium and sulfur. In contrast, the remaining conventional-growth boule, known as LL5, is an early NIF R\&D crystal. It contains very low levels of these impurities and, as shall be seen, offers good damage performance and conditioning.

Generally speaking the samples discussed here are $5 \times 5 \times 1 \mathrm{~cm}^{3}$, type-II tripler-cut samples with diamond-turned surfaces, although some $\mathrm{x}$ - and z-cuts of CD35 were also tested. Tripler cuts are required because of the dramatic difference in the damage probability between THG and z-cut crystals for the same exposure conditions ${ }^{13}$.

\section{TEST RESULTS}

\subsection{The effect of $1 \omega$ scanning on $3 \omega$ damage}

This section gives results for the effect of $1 \omega$ raster scanning on the $3 \omega$-damage performance. For these tests, regions of $40 \times 10 \mathrm{~mm}^{2}$ were scanned using the Zeus $1 \omega, 10$-ns beam at fluences exceeding $30 \mathrm{~J} / \mathrm{cm}^{2}$. The fill factor was 20 shots/site using the $0.9 \mathrm{~F}_{\text {peak }}$ beam diameter. The maximum fluence attainable on these samples was $30 \mathrm{~J} / \mathrm{cm}^{2}$ before significant bulk damage occurred. The system was then switched to $3 \omega$ and $\mathrm{S} / 1$ damage tests were performed. The results of testing in regions of $30 \mathrm{~J} / \mathrm{cm}^{2}$ scan fluence are shown in Figure 2 for two z-plates from CD35. 

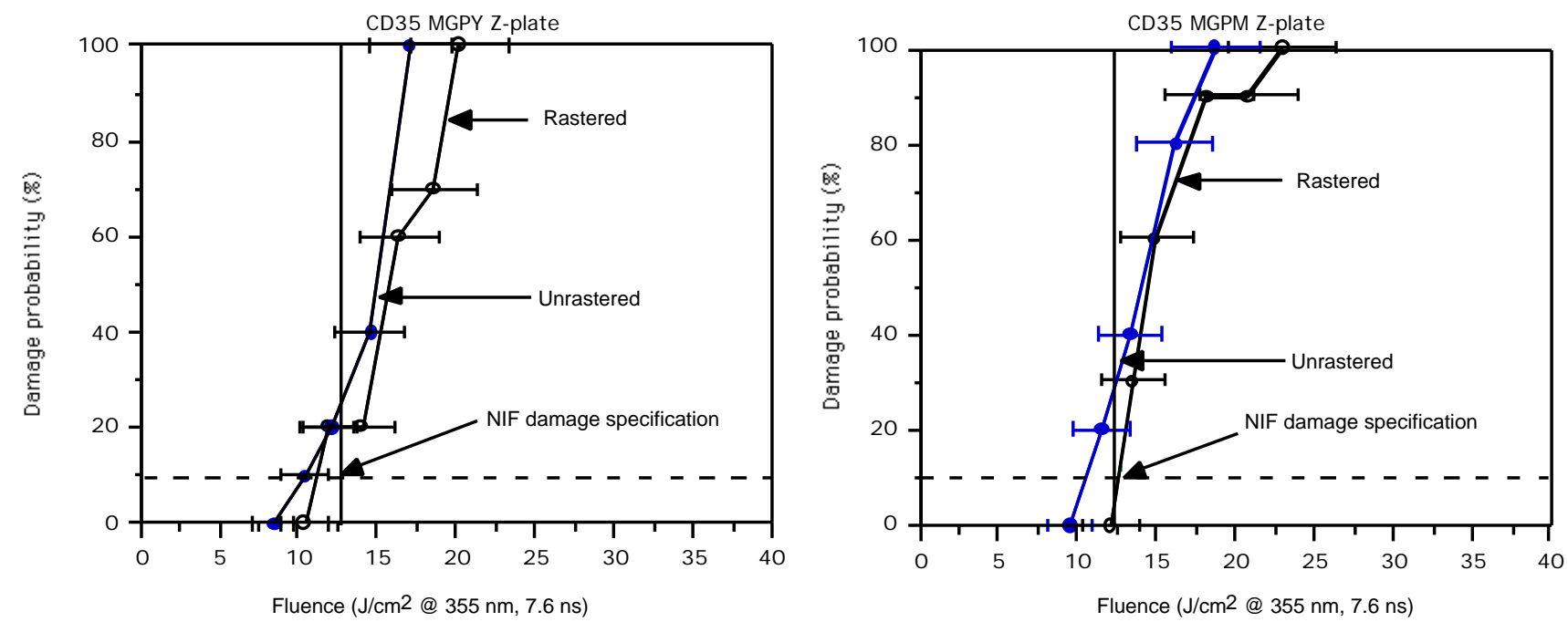

Figure 2. Results of $3 \omega \mathrm{S} / 1$ damage tests on two z-plates from CD35 after raster scanning at $1 \omega \mathrm{with} 30 \mathrm{~J} / \mathrm{cm}^{2}$. There is no measurable increase in damage resistance. The closed circles indicate data from unrastered regions while open circles are data from rastered test regions.

The plots in Figure 2 show that $1 \omega$-scanning has no effect on the damage performance of the material at $355 \mathrm{~nm}$. The $1 \omega$ scans were also repeated on two other rapid-growth type-I doubler cuts from boules KDP189 and RG9B and also did not exhibit any improvement. We have not performed this test on tripler cut material, but based on these results, we do not think there will be an effect.

\subsection{The effect of $3 \omega$ scanning on $1 \omega$ damage}

Several pieces from boule CD35 were used to examine the effect of $3 \omega$ scanning on the $1 \omega$-damage performance. For these tests, low $3 \omega$-fluences of $5 \mathrm{~J} / \mathrm{cm}^{2}(8 \mathrm{~ns})$ were used because previous testing ${ }^{13}$ had shown that CD35 did not possess high $3 \omega$ damage resistance. The $40 \times 10 \mathrm{~mm}^{2}$ scan regions on these samples were scanned starting at $5 \mathrm{~J} / \mathrm{cm}^{2}$ with $0.9 \mathrm{~F}_{\text {peak }}$ fill factors of 20 shots/site. Scans at higher $3 \omega$ fluence were attempted but these resulted in bulk damage at more than $5 \%$ of the sites. After scanning the Zeus laser was reconfigured for $1 \omega$ operation and the samples were tested. The results of the $1 \omega \mathrm{S} / 1$ damage tests are shown in Figure 3.
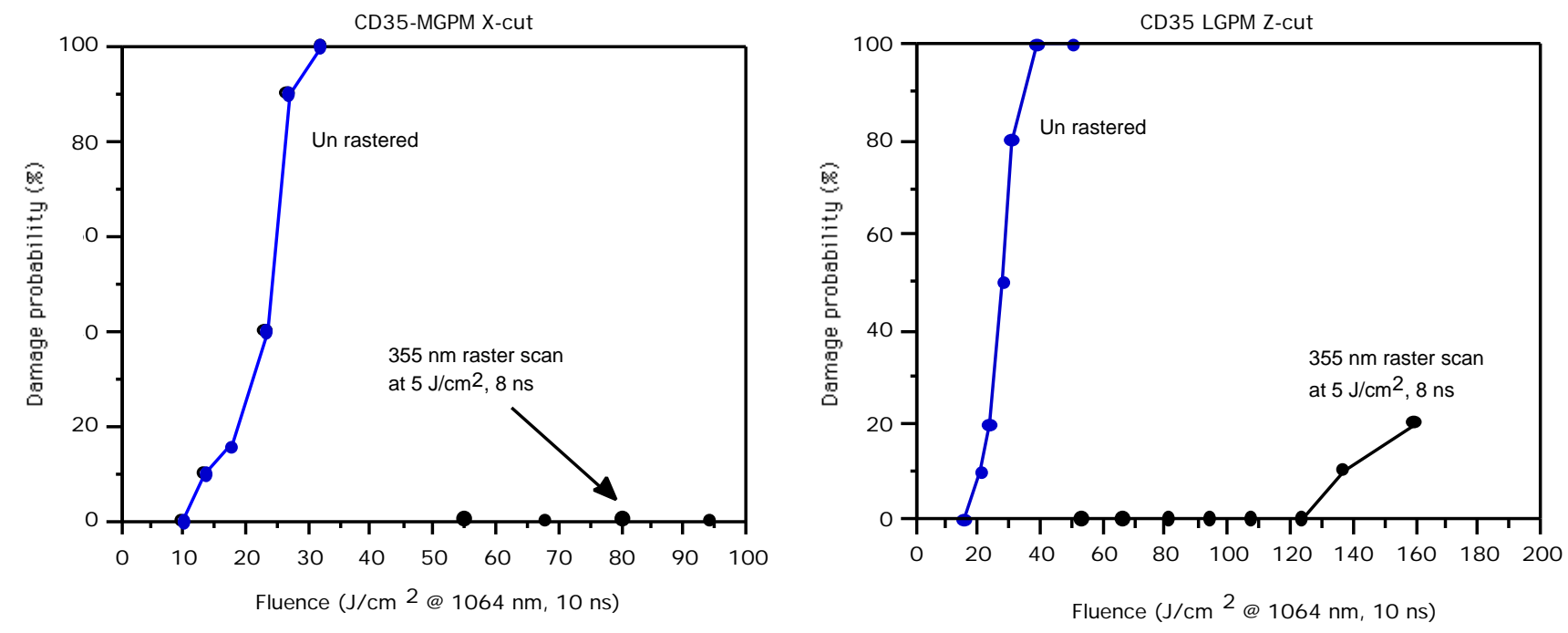

Figure 3. The results of $3 \omega$ raster scanning at $5 \mathrm{~J} / \mathrm{cm}^{2}, 20$ shots/site, on the $1 \omega$ damage performance of CD $35 \mathrm{x}$ - and $\mathrm{z}$-cut crystals. The onset of damage was not observed on either sample until fluences exceeded $120 \mathrm{~J} / \mathrm{cm}^{2}\left(12 \mathrm{GW} / \mathrm{cm}^{2}\right)$. 
As can be seen in Figure 3, there was no damage until $1 \omega$ fluences exceeded $120 \mathrm{~J} / \mathrm{cm}^{2}\left(12 \mathrm{GW} / \mathrm{cm}^{2}\right)$. Results of this type were first seen by Gong et al. ${ }^{14}$ in a preliminary work on raster scanning with excimers, but our effect is much larger.

It is apparent that these results are equally applicable for $\mathrm{x}$-cut crystals as well as z-plates. The fluences at which bulk damage does occur are several times higher than any anticipated for the NIF. Consequently, low-fluence $3 \omega$ raster-scanning of z-plates would render the NIF Pockels cell crystals essentially impervious to laser damage. Treatment of this type would also be very valuable for KDP type-I doubler crystals, and so the experiment was repeated using 46-ns excimer pulses at 308 $\mathrm{nm}$. A sample from rapid-growth KDP boule F6 was scanned. This sample (F6-PM) was divided into 2 scan regions. These received a single pass with 20 shots/site and 11.7 and $22.0 \mathrm{~J} / \mathrm{cm}^{2}$ fluences. After scanning, $\mathrm{S} / 1$ damage tests were performed at $1 \omega$ with and without second-harmonic generation in the samples where the conversion efficiency was between 25 and 30 percent. $^{3}$ The test results are shown in Figure 4.

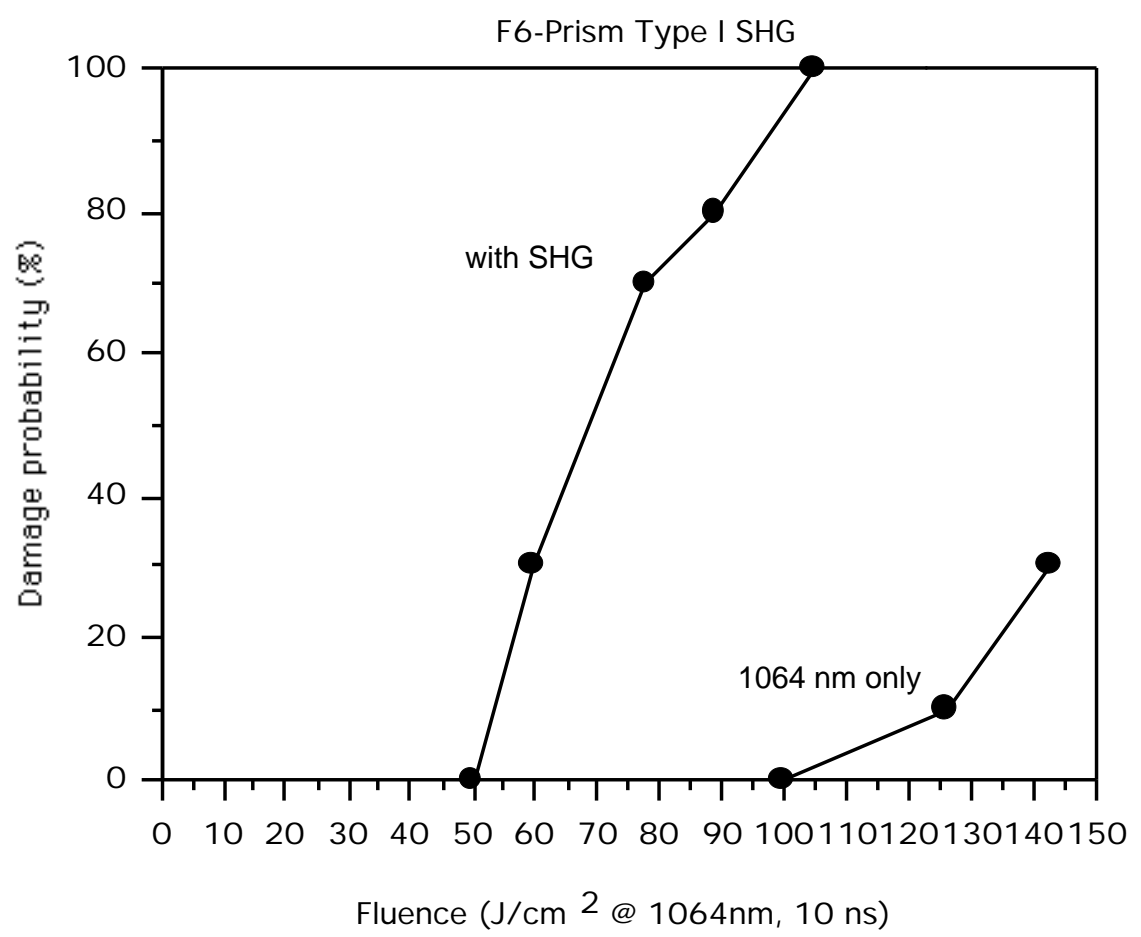

Figure 4. The effect of $308 \mathrm{~nm}$ raster scanning at $22 \mathrm{~J} / \mathrm{cm}^{2}, 46 \mathrm{~ns}$ on the damage performance of rapid-growth SHG crystal from boule F6. Bulk damage for $1 \omega$-only test does not start until $100 \mathrm{~J} / \mathrm{cm}^{2}$ although the SHG process reduces this to $\sim 50 \mathrm{~J} / \mathrm{cm}^{2}$.

The $1 \omega$-only damage tests on the excimer treated samples show very similar response to those raster scanned with $3 \omega$ Nd:YAG. The onset of bulk damage is greater than $100 \mathrm{~J} / \mathrm{cm}^{2}$ and most test sites were resistant to fluences greater than 140 $\mathrm{J} / \mathrm{cm}^{2}$. When second harmonic generation is allowed in the crystal, the damage probability fluences drop by roughly a factor of 2. Bulk damage occurred at fluences greater than $50 \mathrm{~J} / \mathrm{cm}^{2}$. This result is similar to an earlier result for $1 \omega$-conditioned SHGs. ${ }^{3}$ Despite the reduction of damage performance, the SHG curve is still greater than any anticipated NIF fluence or irradiance level. The frequency conversion efficiency for the test conditions was between 25 and $30 \%$. It is an open question whether higher levels of 532-nm generation will reduce the damage fluences even more, though it appears likely, so low fluence conditioning $\left(5-10 \mathrm{~J} / \mathrm{cm}^{2}\right)$ of SHG crystals will be pursued for the NIF.

\subsection{Results of raster scanning using XeCl excimers at $308 \mathrm{~nm}$}

The high energy, rep-rate, and ability to easily shape the beam for scanning uniformity make excimer lasers attractive for raster conditioning of large laser optics. Continued development has brought them to the state of reliability where today they find wide acceptance in photolithography applications where they must run continuously for long periods of time. The first experiments we performed on $\mathrm{KDP}$ with excimers used $\mathrm{XeCl}$ at $308 \mathrm{~nm}$. In principle this was because the $\mathrm{XeCl}$ laser is currently the most highly developed excimer source and offers the highest energy output. In evaluating XeCl conditioning we performed many tests on DKDP material (BD8, CD35, LL5 and LL6 material), with data shown in Table 1 below. Of these, tests done on samples CD35-2 and LL5-C1 were most illustrative. 
Table 1. Results of excimer scan tests. The absorption change for $\mathrm{XeCl}$ and $\mathrm{KrF}$ scanned samples was measured from photometry data and could be averaged over the scanned regions. The absorption change for XeF scanned samples was measured from UV absorption spectra. Spectra were obtained from six regions on each crystal before and after scanning, but the regions could not be readily associated with specific scan regions. Therefore the maximum change measured is listed.

\begin{tabular}{|c|c|c|c|c|c|}
\hline DKDP Sample & $\begin{array}{c}\text { Excimer } \\
\text { scan type } \\
\end{array}$ & $\begin{array}{c}\text { Scan fluence } \\
\left(\mathrm{J} / \mathrm{cm}^{2} \text { at } 308 \mathrm{~nm}\right) \\
\end{array}$ & Fill Factor & $\begin{array}{c}\begin{array}{c}\text { Degree of } \\
\text { conditioning }\end{array} \\
\end{array}$ & Absorption change @ 351-nm \\
\hline $308 \mathrm{~nm}$ & & & & & Photometry data \\
\hline \multirow[t]{2}{*}{ BD8-2 } & Fluence & 11.7 & 34 & 1.0 & $1.2 \mathrm{X}$ \\
\hline & & $11.7+22$ & 34 & 1.4 & $1.2 \mathrm{X}$ \\
\hline \multirow[t]{2}{*}{ CD35-2 } & Fluence & 8.8 & 34 & 1.2 & $4.9 \mathrm{X}$ \\
\hline & & $8.8+17.6$ & 34 & 1.6 & $4.0 \mathrm{X}$ \\
\hline \multirow{2}{*}{ LL5-C1 } & & $8.8+17.6$ & 34 & 2.4 & $1.3 \mathrm{X}$ \\
\hline & & $8.8+17.6+24.9$ & 34 & 2.0 & $1.3 \mathrm{X}$ \\
\hline \multirow[t]{2}{*}{ LL6-2 } & Fluence & 11.7 & 34 & 1.1 & $4.6 \mathrm{X}$ \\
\hline & & $11.7+26.4$ & 34 & 1.7 & $6.1 \mathrm{X}$ \\
\hline \multicolumn{6}{|l|}{$248 \mathrm{~nm}$} \\
\hline $351 \mathrm{~nm}$ & & & & & UV spectra data \\
\hline \multirow[t]{3}{*}{ CD35-2 XeF } & Fluence & 12.2 & 284 & 1.1 & \multirow{3}{*}{$1.9 \mathrm{X}$ maximum } \\
\hline & & $12.2+22.4$ & 284 & 1.6 & \\
\hline & & $12.2+22.4+36.7$ & 284 & 2.1 & \\
\hline CD35-3 XeF & Step-rate & 30.6 & 47 & 1.6 & \multirow{3}{*}{$1.7 \mathrm{X}$ maximum } \\
\hline & & 30.6 & 94 & 1.8 & \\
\hline & & 30.6 & 189 & 1.8 & \\
\hline \multirow[t]{3}{*}{ LL5-1 XeF } & Fluence & 16.3 & 284 & 1.5 & \multirow{3}{*}{$1.1 \mathrm{X}$ maximum } \\
\hline & & $16.3+30.6$ & 284 & 2.2 & \\
\hline & & $16.3+30.6+44.8$ & 284 & 1.7 & \\
\hline LL5-2 XeF & Step-rate & 44.8 & 47 & 1.5 & $2.6 \mathrm{X}$ maximum \\
\hline
\end{tabular}

A "fluence scan" was performed on CD35-2 where a $40 \times 30 \mathrm{~mm}^{2}$ region was scanned at $8.8 \mathrm{~J} / \mathrm{cm}^{2}$ with 20 shots/site fill factor. Two thirds of this region was then scanned at $17.6 \mathrm{~J} / \mathrm{cm}^{2}$ and the remaining third scanned at $20.6 \mathrm{~J} / \mathrm{cm}^{2}$. UV absorption spectra had been taken before and after scanning along with a photometry map at $350 \mathrm{~nm}$ before damage testing. The photometry scan and S/1 damage data is shown in Figure 5.
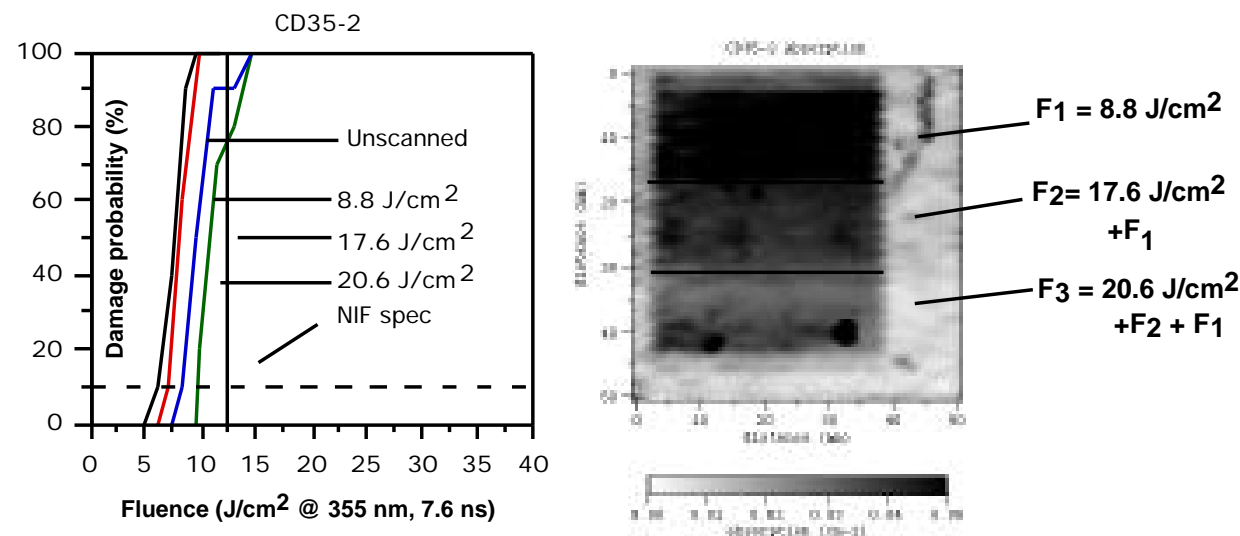

Figure 5. S/1 damage data (left plot) and 350-nm photometry scan (right plot) for 308-nm excimer-scanned sample CD35-2. Maximum conditioning of $1.6 \mathrm{X}$ was attained in the two-fluence scan to $17.6 \mathrm{~J} / \mathrm{cm}^{2}$, but scanning increased the absorption at $350 \mathrm{~nm}$ by $3-5 X$. 
The $\mathrm{S} / 1$ test data shows that damage resistance is maximized at $1.6 \mathrm{X}$ for the two-fluence scan to $17.6 \mathrm{~J} / \mathrm{cm}^{2}$ and drops to $1.4 \mathrm{X}$ for the three-fluence scan to $20.2 \mathrm{~J} / \mathrm{cm}^{2}$. The photometry scan shows that the single-fluence scan to $8.8 \mathrm{~J} / \mathrm{cm}^{2}$ increases the 350-nm absorption by $5 \mathrm{X}$. The absorption bleaches to $\sim 3 \mathrm{X}$ over its unscanned value for the three-fluence scan to 20.6 $\mathrm{J} / \mathrm{cm}^{2}$. Thermal annealing of this sample at $110^{\circ} \mathrm{C}$ for 1 week did not affect the UV absorption.

The damage performance of LL5-C1 was significantly improved. A fluence scan was performed on this sample at $8.8 \mathrm{~J} / \mathrm{cm}^{2}$, $8.8+17.6 \mathrm{~J} / \mathrm{cm}^{2}$ and $8.8+17.6+32.3 \mathrm{~J} / \mathrm{cm}^{2}$ with fill factor of 20 shots/site. The S/1 damage test data and photometry scan are shown in Figure 6. This sample exhibits maximum conditioning (2.4X) in the two-fluence scan to $17.6 \mathrm{~J} / \mathrm{cm}^{2}$, and it has a much higher degree of conditioning than CD35-2. The degree of conditioning achieved exceeds the NIF damage specification of $10 \%$ damage probability at $12.5 \mathrm{~J} / \mathrm{cm}^{2}, 8 \mathrm{~ns}$. The three-fluence scan to $24.9 \mathrm{~J} / \mathrm{cm}^{2}$ yields $2.0 X$ conditioning and this also meets the NIF damage specification. The photometry scan indicates a maximum increase of $1.5 \mathrm{X}$ in $350-\mathrm{nm}$ absorption occurred as a result of scanning.
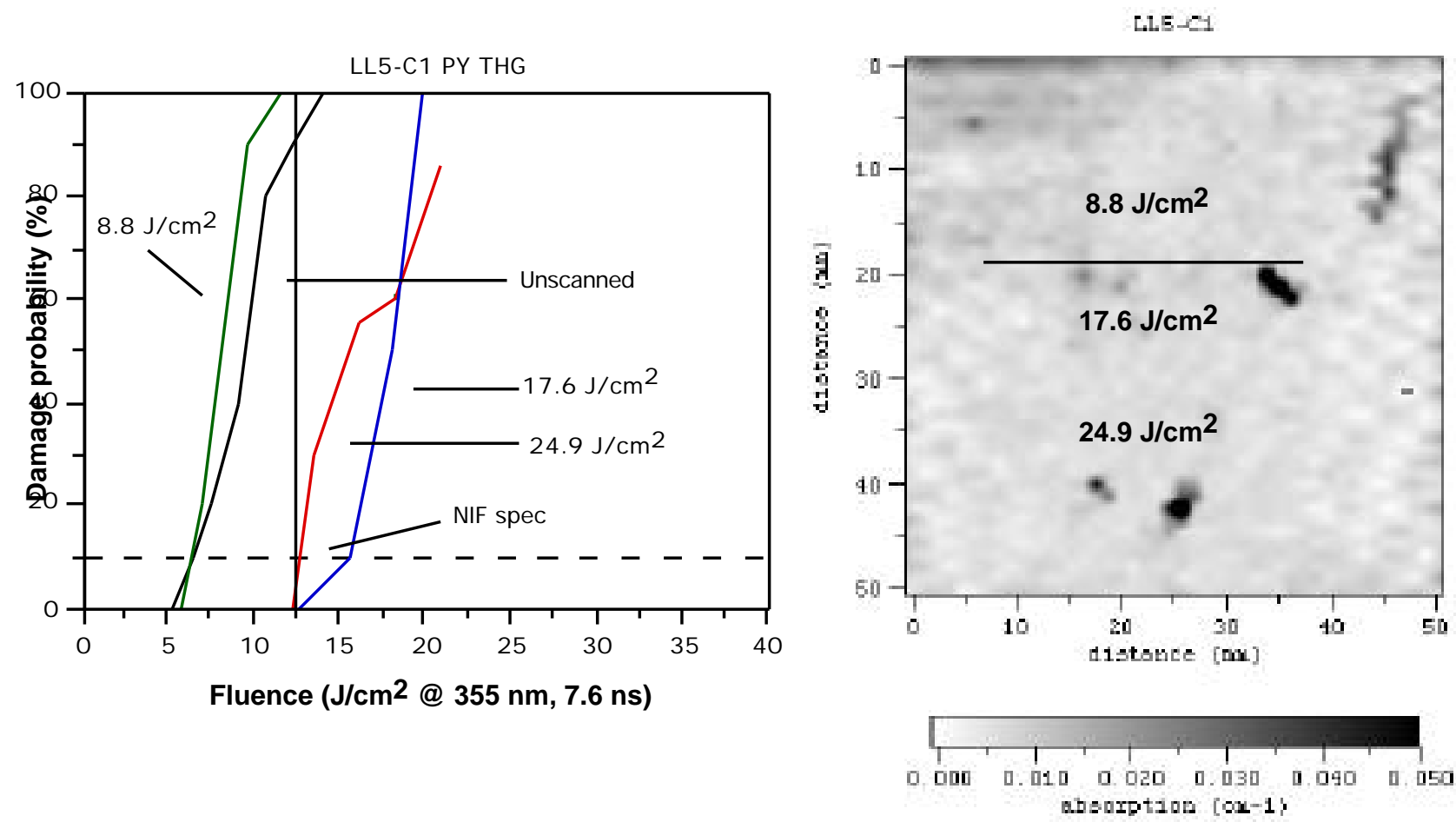

Figure 6. S/1 test data (left plot) and $350 \mathrm{~nm}$ photometry scan (right plot) for conventional-growth sample LL5-C1. Conditioning at $308 \mathrm{~nm}$ reaches a maximum in the two-fluence scan to $17.6 \mathrm{~J} / \mathrm{cm}^{2}$, but there is no significant induced absorption at $350 \mathrm{~nm}$.

The degree of conditioning for fluence scans on samples BD8-2 in a two-fluence scan $\left(11.7+22.0 \mathrm{~J} / \mathrm{cm}^{2}\right)$ was $1.4 \mathrm{X}$ while for LL6-2 the two-fluence scan $\left(11.7+26.4 \mathrm{~J} / \mathrm{cm}^{2}\right)$ yielded $1.7 \mathrm{X}$ conditioning. For this limited parameter range, both exhibited increases in 350-nm absorption of 1.2X. The absorption for BD8-2 at shorter wavelengths was actually reduced for these scan parameters and is shown in Figure 7. 
Rapid growth

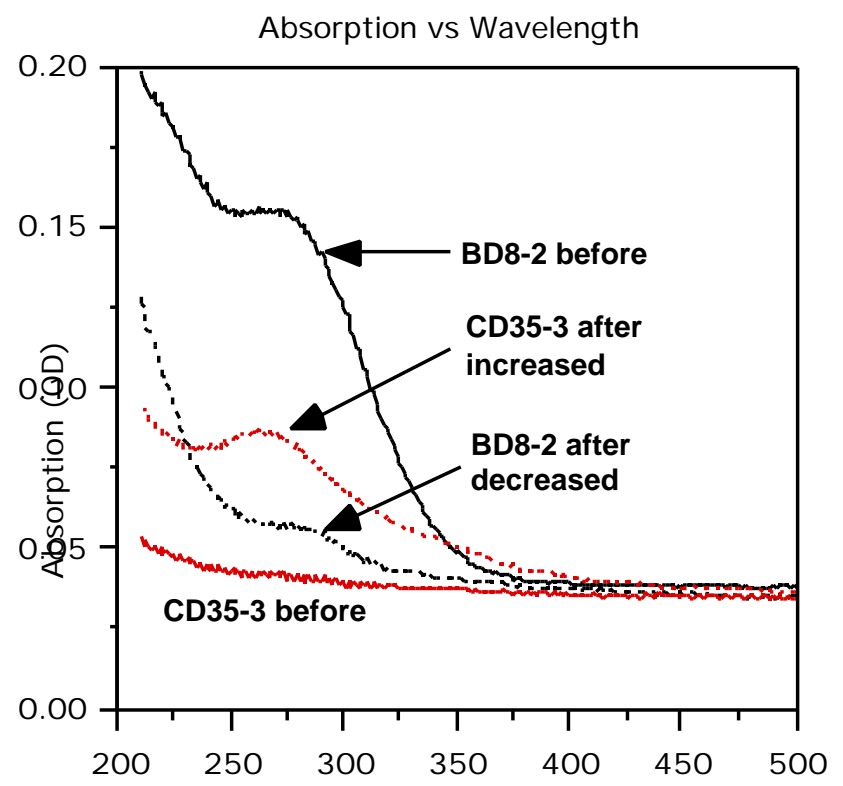

Wavelength $(\mathrm{nm})$
Conventional growth

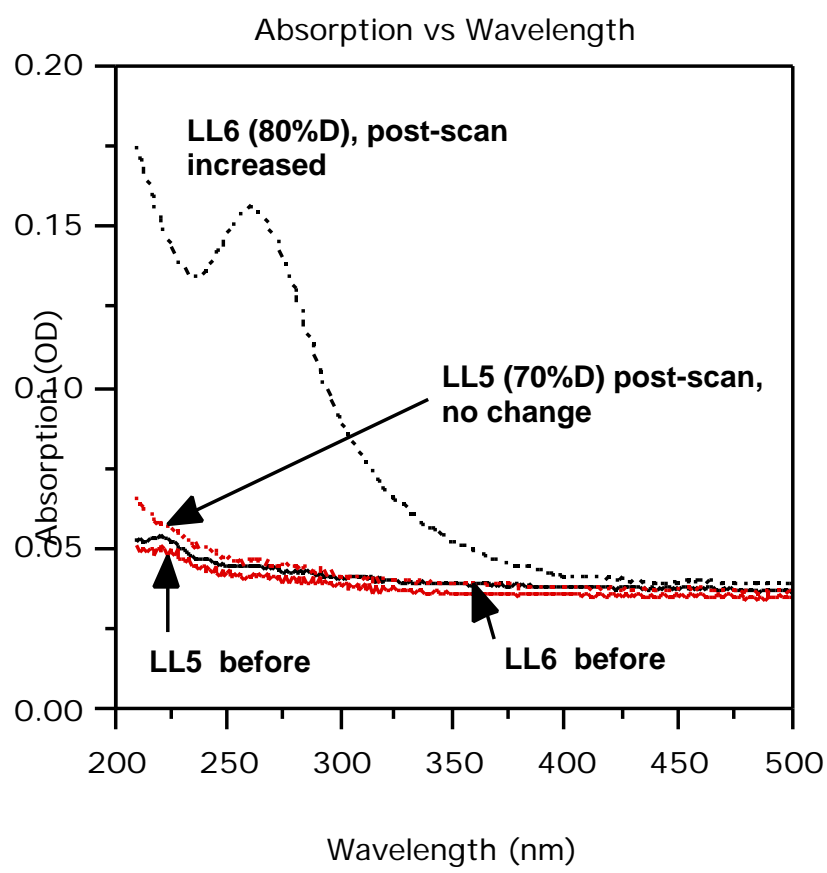

Figure 7. Absorption spectra for BD8-2, CD35-2, LL5-C1 and LL6-2 before and after 308-nm scanning. There are dramatic differences in the amount of induced absorption at wavelength shorter than $350 \mathrm{~nm}$. BD8-2 shows a reduction of absorption while LL5 shows essentially no change.

The degree of absorption seen in the different crystal boules varies dramatically. The BD8 material shows a reduction in the initial absorption at wavelengths less than $350 \mathrm{~nm}$. This bleaching was also observed by Gong et al. ${ }^{14}$ In contrast, the conventional-growth LL6 material showed the largest increase in absorption and displayed a very pronounced peak at 260 $\mathrm{nm}$. This sample was known to have high concentrations of arsenic, rubidium and sulfur. Arsenic has been proposed as the primary species responsible for the induced absorption based on work done by Marshall et al. ${ }^{15}$ and Levchenko et al. ${ }^{16}$

It is clear that despite the typical increase in damage performance of 1.6 to $2.4 \mathrm{X}$ using $\mathrm{XeCl}$ lasers, the absorption induced in the samples is too variable to make it an ideal candidate for off-line scanning. Two samples were also lost due to thermallyinduced bulk fracture. It would take significant investigation into the root causes of the induced absorption, and references 15 and 16 indicate that there may be many species responsible. Attempting to control these species during the growth process may also lead to other undesirable characteristics. It is therefore worthwhile to find another wavelength where excimer scanning might be successful. With this in mind, we scanned two samples at $248 \mathrm{~nm}$.

\subsection{Results of raster scanning using $248 \mathrm{~nm} \mathrm{KrF} \mathrm{excimers}$}

Two samples were scanned at $248 \mathrm{~nm}$. The first was CD35-4B and it received a two-fluence scan at 11.3 and $17.6 \mathrm{~J} / \mathrm{cm}^{2}$. The fill factor for the tests was 20 shots/site for the beams short-axis FWHM value. The damage resistance of this sample increased by $2.0 \mathrm{X}$ for both the single fluence pass at $11.3 \mathrm{~J} / \mathrm{cm}^{2}$ and the two-fluence pass to $17.6 \mathrm{~J} / \mathrm{cm}^{2}$. Photometry scans of this sample at $350 \mathrm{~nm}$ showed levels of absorption comparable to the 308-nm scanning case.

The second sample, LL6-3 also received a two-fluence scan where the fluences were 12.5 and $25 \mathrm{~J} / \mathrm{cm}^{2}$. The single-fluence pass at 20 shots/site yielded only $1.2 \mathrm{X}$ conditioning while the two-fluence scan yielded an increase of $1.7 \mathrm{X}$. The increase in 350-nm absorption for both single- and double-fluence tests was 4.8X. In addition, this sample suffered a deep bulk fracture that was the result of thermal stress in the vicinity of the scanning beam. Thermal modeling calculations showed that with absorption coefficients of $0.25 \mathrm{~cm}^{-1}$ the local temperature rise for the material under the beam could be as high as $60^{\circ} \mathrm{C}$ at 20 shots/site scan speeds. This is enough to cause a thermal-shock fracture to DKDP. The photometry scan for sample LL6-3 is shown in Figure 8. 



Figure 8. S/1 damage data (left plot) and 350-nm photometry scan for conventional-growth sample LL6-3. The sample was scanned at 12.5 and $25.1 \mathrm{~J} / \mathrm{cm}^{2}$ with 248 -nm laser light and showed conditioning of $1.2 \mathrm{X}$ and 1.7X. The 350-nm absorption induced by KrF was comparable to the $\mathrm{XeCl}$ results but the higher absorption $\left(\sim 0.25 \mathrm{~cm}^{-1}\right.$ at $\left.248 \mathrm{~nm}\right)$ resulted in the bulk fracture due to local thermal stress.

The damage data for LL6-3 show 1.2 and 1.7X increases due to raster scanning which is quite typical for this material as is the level of induced absorption at $350 \mathrm{~nm}$. The bulk fracture due to thermal stress eliminates $\mathrm{KrF}$ as a possible scanning wavelength.

\subsection{Results of raster scanning at 351-nm using XeF excimers}

The induced absorption and bulk thermal fracture observed at 308 and $248 \mathrm{~nm}$ effectively eliminate these wavelengths from consideration for a practical scanning system, at least with the current state of knowledge. The XeF line at 351-nm remains as the only viable candidate for scanning systems. To test the effectiveness of this excimer line, we scanned samples of CD35 and LL5. In addition to the fluence scans, so-called step rate scans were performed as well. In these, the stage velocity in each region was adjusted to give a different fluence dosage for the same peak fluence. UV absorption spectra were also taken before and after scanning on the samples. The spectra were taken at six different locations on each sample, but the changes seen due to scanning have not been correlated to the scan doses and fluences. Therefore the data that appear in Table 1 represent the maximum change that was observed in any of the UV spectra regions as a result of raster scanning.

CD35-2 fluence scan - A fluence scan was performed on CD35-2. Initially, the entire scan region was irradiated at 12.2 $\mathrm{J} / \mathrm{cm}^{2}$. Two-thirds of this region was scanned at $24.4 \mathrm{~J} / \mathrm{cm}^{2}$ and the remaining one third was scanned at $36.7 \mathrm{~J} / \mathrm{cm}^{2}$. The stage velocity was $0.2 \mathrm{~mm} / \mathrm{s}$ and laser rep rate was $150 \mathrm{~Hz}$. Accordingly the fill factor for all scans was 283.5 shots/site. This fill factor was chosen to approximate the fluence ramp that occurs during a Zeus R/1 damage test to determine whether the same (large) degree of conditioning could be achieved with excimer raster scanning. Only two damage sites were observed in the $12.2 \mathrm{~J} / \mathrm{cm}^{2}$ only scan region. This number climbed to $\sim 15$ for the $12.2+24.4 \mathrm{~J} / \mathrm{cm}^{2}$ region and rose to approximately 100 in the three-fluence scan region, where we also observed 4-6 surface sites. The 100 bulk sites correspond to a density of $0.03 \mathrm{pp} / \mathrm{mm}^{3}$, which is at least 100X lower than allowed. This is shown in Figure 9. 


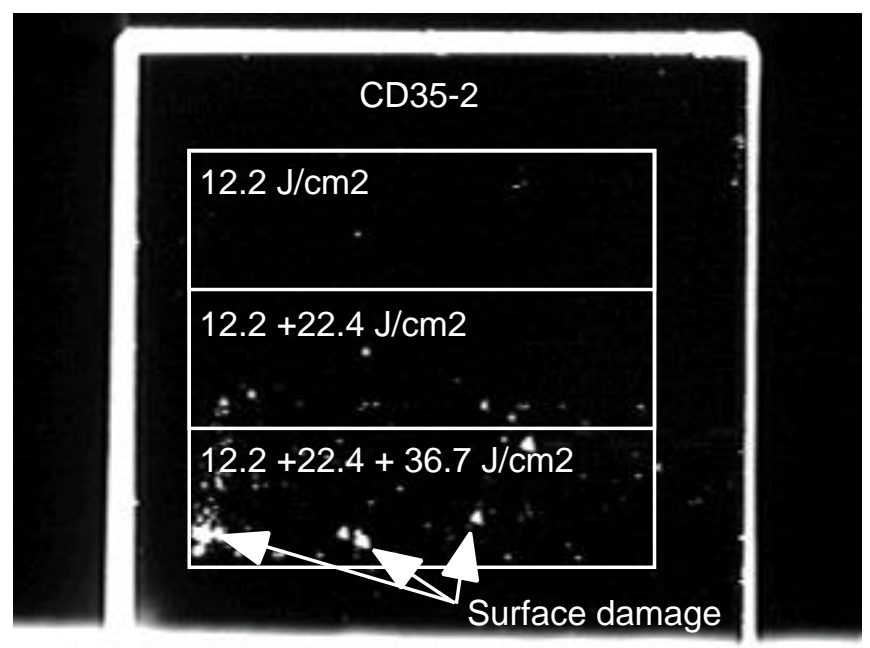

Figure 9. Darkfield image of CD35-2 after XeF raster scanning. Bulk damage levels increase with fluence, but there appears to be a threshold for surface damage initiation between 22.4 and $36.7 \mathrm{~J} / \mathrm{cm}^{2}$.

UV absorption spectra were also taken after scanning in each region. Despite the high fluence dosage given to this sample there was only a $2.0 \mathrm{X}$ increase in the 351-nm absorption. This change is comparable to that seen for samples scanned with $\mathrm{XeCl}$ and $\mathrm{KrF}$, but the increase in absorption at shorter wavelengths is substantially lower than that seen for $\mathrm{XeCl}$ and $\mathrm{KrF}$ scanned samples (see Figure 7). The pre- and post-scan spectra for XeCl scanned CD35-2 are shown in Figure 10.
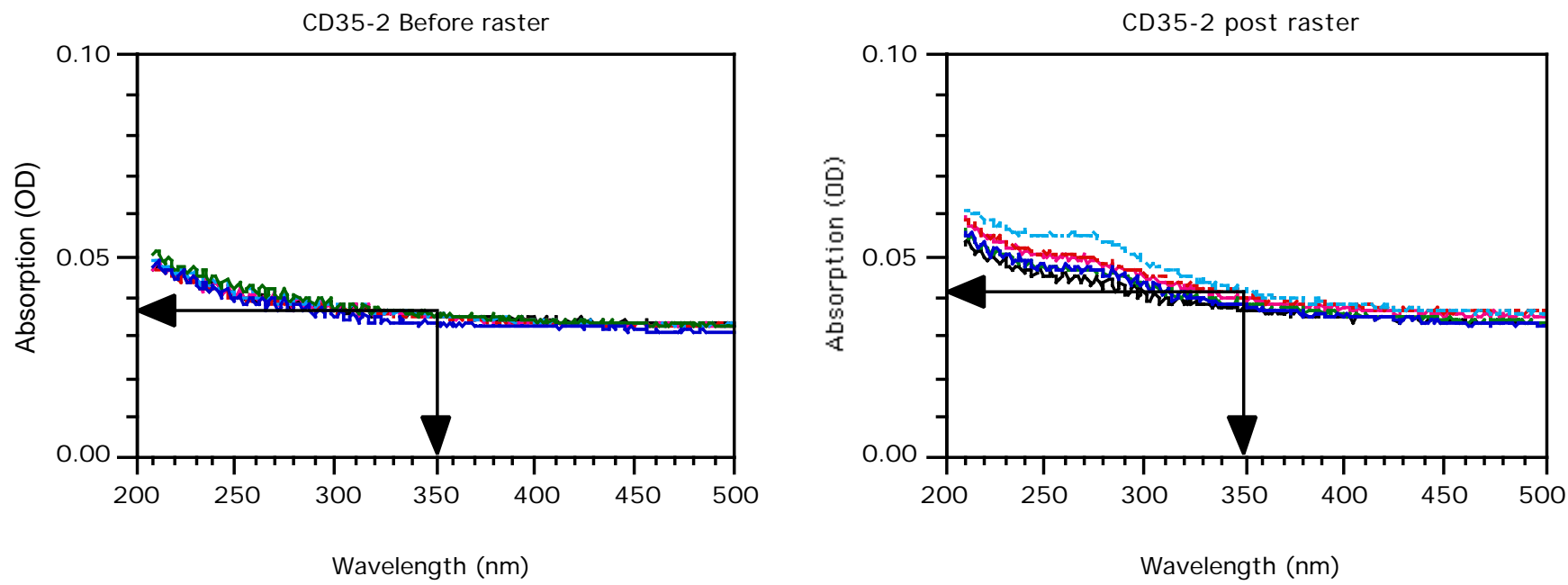

Figure 10. UV absorption spectra of CD35-2 given in OD. The maximum change in absorption (base 10) due to 351-nm scanning was $1.9 \mathrm{X}$ from $0.006 \mathrm{~cm}^{-1}$ to $0.0114 \mathrm{~cm}^{-1}$. The absorption values have been extracted from normalized spectra and account for the Fresnel surface losses while the data shown in the plot are the raw, unnormalized spectra and have not been corrected for Fresnel losses.

S/1 damage tests were performed in each region. There was a $1.1 \mathrm{X}$ increase in the $10 \%$ damage probability fluence for the $12.2 \mathrm{~J} / \mathrm{cm}^{2}$ scan region while the two and three fluence regions showed increases of 1.6 and $2.1 \mathrm{X}$ respectively. In the latter case, the $\mathrm{S} / 1$ damage probability curve nears the R/1 damage curve from previous Zeus testing. This indicates that it is possible to approach R/1 performance (considered optimal) using excimer scanning. The damage curves are shown in Figure 11 below. 


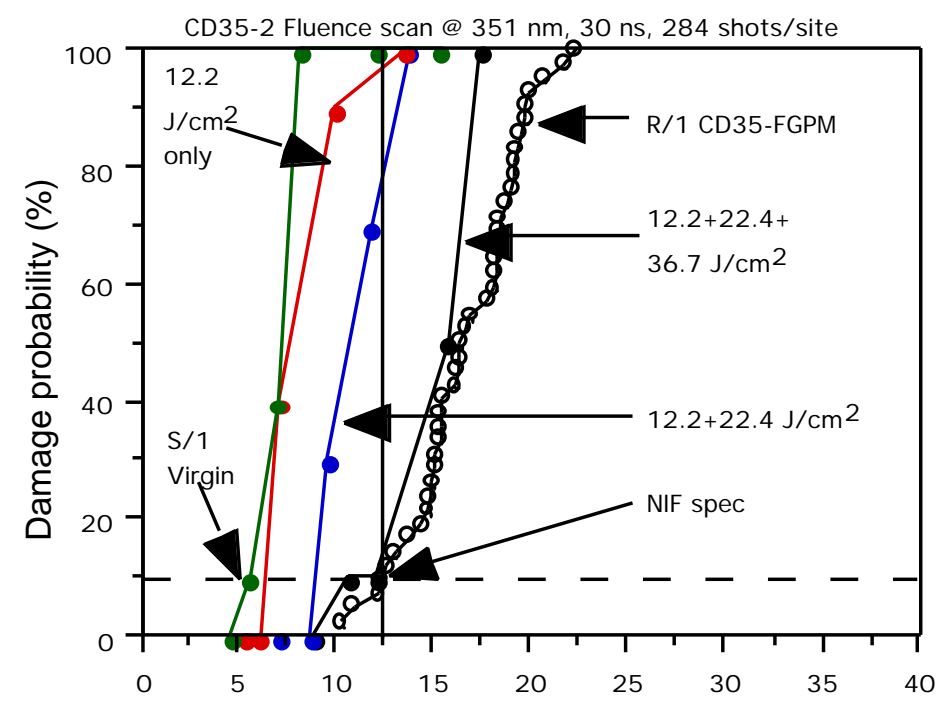

Fluence $\left(\mathrm{J} / \mathrm{cm}^{2} @ 355 \mathrm{~nm}, 7.6 \mathrm{~ns}\right)$

Figure 11. S/1 damage plot for CD35-2. The 3-step scan to $36.7 \mathrm{~J} / \mathrm{cm}^{2}$ shows that the sample can be conditioned to essentially the same level as achievable in the Zeus R/1 test. This would meet the proposed NIF damage spec of $10 \%$ damage probability at 12.5 $\mathrm{J} / \mathrm{cm}^{2}$ for $7.6 \mathrm{~ns}$ pulses. Fluence measurement error bars are not shown.

CD35-3 step rate scan - This test was performed to examine the effect of fill factor at fixed fluence. Each scan region in this sample was rastered at $30.6 \mathrm{~J} / \mathrm{cm}^{2}$. The fill factor for region 1,2 and 3 were 47,94 and 189 shots/site respectively (20, 50 and 100 shots/site for the FWHM value of $200 \mu \mathrm{m})$. The effect of conditioning due to increased fill factor can be seen in Figure 12. In the 47 shot/site region, there is substantial bulk damage ( 200 pinpoints) while the occurrence of damage dropped to $\sim 10$ and 4 sites in the 94 and 189 shots/site regions. No surface damage was observed for any of the scanned regions.
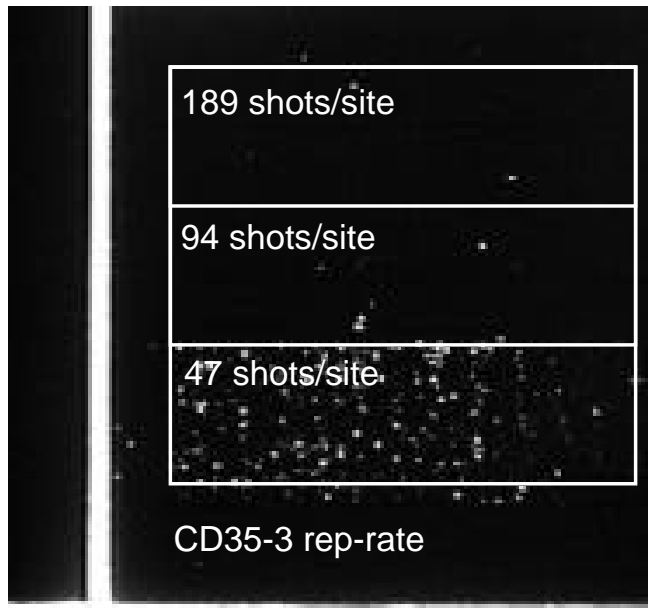

\section{CD35-3 rep-rate}

Figure 12. Darkfield photograph of CD35-3 showing the reduction in bulk damage as a function of fill factor for scan fluence of $30.6 \mathrm{~J} / \mathrm{cm}^{2}$. The pinpoint density in the 47 -shots/site region is approximately $0.05 \mathrm{pp} / \mathrm{mm}^{3}$, which is approximately 100 times less than allowed.

There was a slight increase in UV absorption due to the scanning. The post-scan spectra are essentially identical to those from CD35-2, and the largest change in 350-nm absorption due to the XeF scans was $1.7 \mathrm{X}$ from $0.007 \mathrm{~cm}^{-1}$ to $0.0118 \mathrm{~cm}^{-1}$. 
Figure 13 shows the S/1 damage probability plots for this sample. As can be seen, the increase due to 47 shots/site conditioning was $1.6 \mathrm{X}$ while for 94 and 189 shots/site it was $1.8 \mathrm{X}$. We currently do not understand why the 47 shot/site damage curve crosses over the other two at $\sim 10 \mathrm{~J} / \mathrm{cm}^{2}$. It is possible that this is a statistical anomaly ${ }^{10}$.

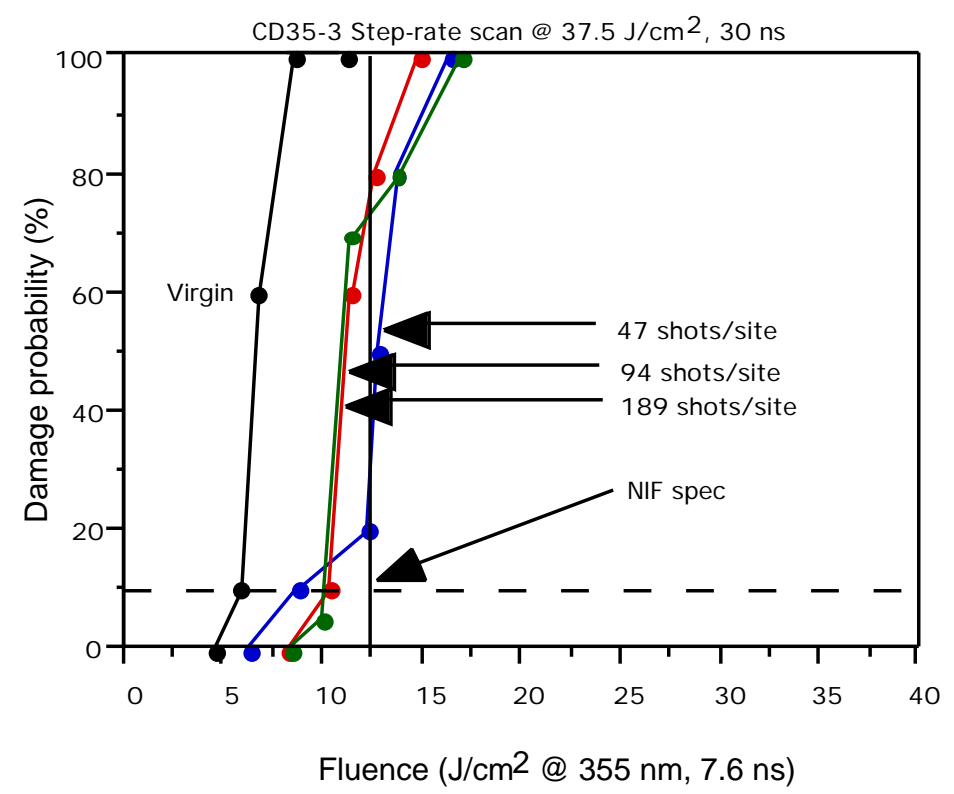

Figure 13. S/1 damage plot for CD35-3 showing the level of conditioning achieved by rep-rate scanning.

LL5-1 fluence scan - Fluence scans were performed on this sample at $16.3,16.3+30.6$ and $16.3+30.6+44.8 \mathrm{~J} / \mathrm{cm}^{2}$. The fill factor for all regions was 284 shots/sites. The fluences for this test were higher than for CD35 because LL5 has better damage performance and exhibits a very high degree of conditioning for Zeus S/1 and R/1 tests (2.9 X). There were on the order of 10 bulk damage sites in the first scan region. This increased in the second $\left(16.3+30.6 \mathrm{~J} / \mathrm{cm}^{2}\right)$ region where some enhancement of existing surface scratches was observed along with 2-3 surface damage sites. The number of bulk damage sites seen in the third scan region $\left(16.3+30.6+44.8 \mathrm{~J} / \mathrm{cm}^{2}\right)$ increased to about $100\left(0.025 / \mathrm{mm}^{3}\right)$ and there were 6 major surface damage sites that tended to propagate as the sample moved under the scan beam.

The post-raster UV spectrum showed that there was virtually no increase in the overall UV absorption and no features were brought out in the deeper UV region (as was the case with CD35). The maximum increase in 351-nm absorption was less than the change seen in this material for previous $\mathrm{XeCl}$ scanning at $308 \mathrm{~nm}$.

The damage probability curves showed an increase in the $10 \%$ damage fluence of $1.3,1.4$ and $1.5 \mathrm{X}$ for the single, double and triple fluence regions respectively. While the conditioning was rather modest for this sample, the conditioned damage probability curves all met or exceeded the proposed NIF damage specification of $10 \%$ damage probability at $12.5 \mathrm{~J} / \mathrm{cm}^{2}, 7.6$ ns. This is shown in Figure 14. 


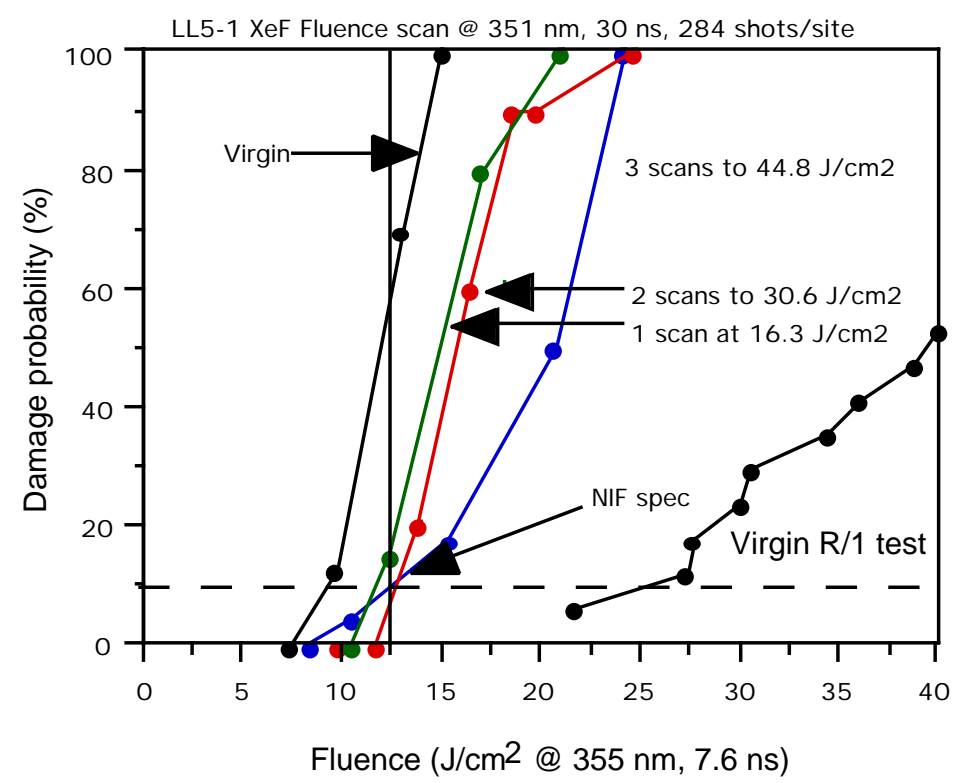

Figure 14. Damage plot for LL5-1 fluence scans. All fluence scans were capable of raising the S/1 damage performance to or beyond the NIF specification. Despite the high fill factor, XeF scanning did not achieve the (extraordinarily) high level of conditioning seen in Zeus R/1 testing.

LL5-2 rep rate scan - Rep rate scans were performed on this sample with each region seeing the maximum available fluence of $44.8 \mathrm{~J} / \mathrm{cm}^{2}$. The fill factors were 47, 94 and 189 shots/site respectively. Although LL5 showed high unconditioned damage resistance, we expected to see some bulk damage during excimer raster scanning due to the high scan fluence. This was the case, particularly for the 47 shots/site region where 100 bulk damage sites formed. Bulk damage densities were slightly reduced in the other regions due to the higher fill factors. In contrast, there was significant enhancement of surface features, notably e-cracks (surface cracking along the extraordinary axis) and scratches in all regions and some surface events. The darkfield photo shown in Figure 15 indicates that surface damage is more prevalent in the regions with higher fill factor. This was not entirely unexpected as it seems that there is a surface damage threshold between 30 and $35 \mathrm{~J} / \mathrm{cm}^{2}$ for both LL5 and CD35 material.
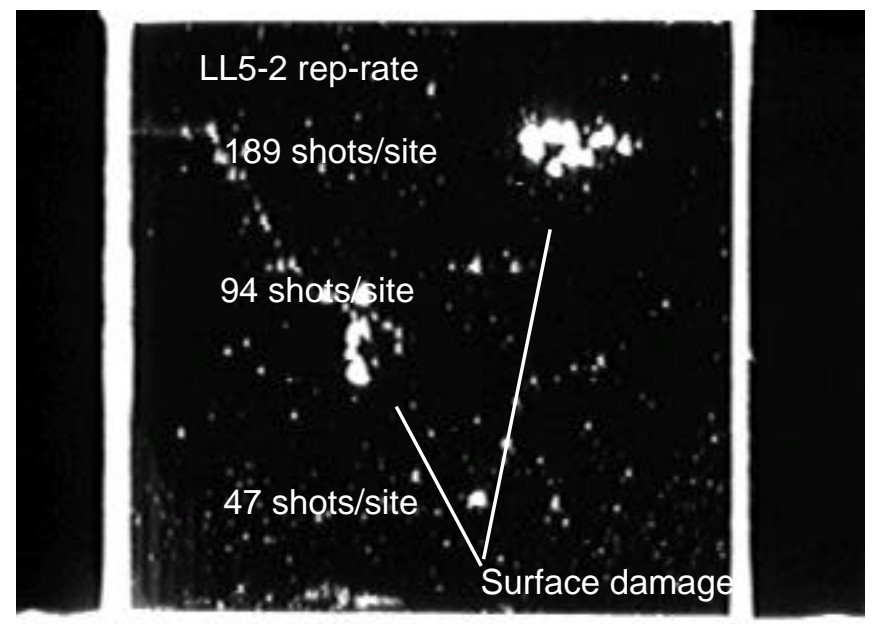

Figure 15. Darkfield photograph of LL5-2 after rep-rate scanning at $44.8 \mathrm{~J} / \mathrm{cm}^{2}$. This fluence was chosen because of the high initial damage resistance and large conditioning seen for this material in testing on the Zeus system. 
UV spectral scans showed very similar behavior to LL5-1 in that there was only a maximum increase of $2.6 \mathrm{X}$ in the UV absorption at 351-nm, from 0.005 to $0.013 \mathrm{~cm}^{-1}$. This may have been due in part to the higher amount of surface scatter seen on LL5-2 because of the higher degree of surface damage. The damage probability curves for S/1 testing at 7.6 ns show that all three fill factors yield significant conditioning. The increase for the 47 shots/site region is $1.5 \mathrm{X}$ while for the 94 and 189 shots/site regions it is 2.2 and 1.7X respectively. This is shown in Figure 16.

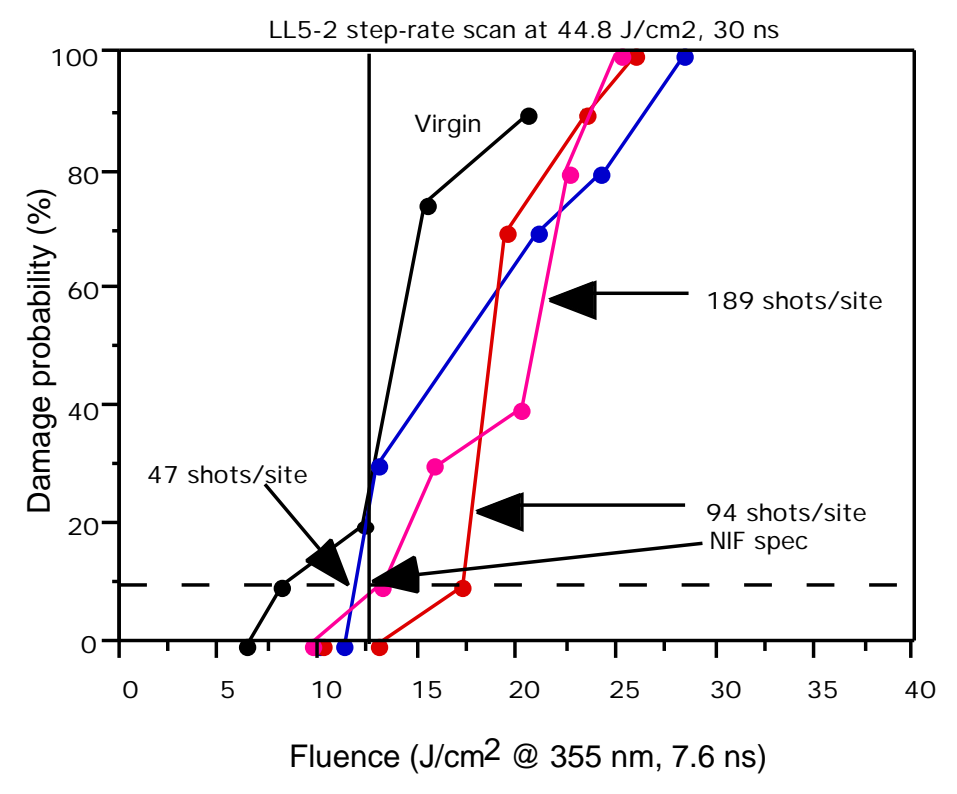

Figure 16. S/1 damage plot for LL5-2 after rep-rate scanning at $44.8 \mathrm{~J} / \mathrm{cm}^{2}$ with fill-factors up to 189 shots/site. The data show that 94 shots/site yields maximum conditioning.

\section{DISCUSSION AND SUMMARY}

The results presented in this paper show that it is possible to increase the damage performance of KDP and DKDP, whether rapid- or conventional-growth, by raster scanning with pulsed UV lasers. Specifically, it is possible to attain dramatic increases in $1 \omega$ damage resistance with low fluence $\left(5 \mathrm{~J} / \mathrm{cm}^{2}\right) 3 \omega$ scanning. The degree of conditioning seen on doubler and Pockels cell cuts of KDP should render the samples virtually damage-proof for NIF fluences. The average degree of conditioning attained using excimer or tripled Nd:YAG irradiation is up to $2 \mathrm{X}$ for $3 \omega$ damage performance, and does not appear to be a function of (UV) wavelength. Indeed, crystals scanned with the deeper UV excimer lines from $\operatorname{KrF}(248 \mathrm{~nm})$ and $\mathrm{XeCl}(308 \mathrm{~nm})$ are susceptible to thermal heating from induced absorption leading to deep bulk fracture at modest fluence doses. These effects were not seen when using XeF at 351-nm even when fluence doses were quite high. Therefore we conclude that $\mathrm{XeF}$ is the most suitable excimer line for raster conditioning of KDP and DKDP.

We have also seen that the degree-of-conditioning as well as the optimal conditioning procedure appear to be highly variable from boule to boule. There does not appear to be a connection between the induced absorption and level of conditioning. It would be highly desirable to develop a model whereby the optimal scan procedure can be set based on a measurable characteristic of the sample, however, no model currently exists, in part because extensive data is not yet available. We will address this situation in a pilot production facility using XeF and tripled Nd:YAG lasers that is currently under construction. This will allow us to increase the number of experiments and also to do them on material more representative of that which will be used in the coming generation of high peak power ICF laser systems. In addition, we will be able to evaluate whether raster scanning by $\mathrm{XeF}$, with its $30 \mathrm{~ns}$ pulse duration is as effective as scanning using a $3 \mathrm{~ns}$ tripled Nd:YAG. This facility will also enable us to develop a full-scale production scanning facility for the NIF.

\section{ACKNOWLEDGMENTS}

The authors would like to thank Pam Whitman for contributing a number of the test samples, Ken Foster for cleaning and mapping the samples, Greg Rogowski and Sue Locke for their assistance in shipping and Linda Ortega for administrative 
support. We would also like to thank our colleagues Peter Oesterlin, Berthold Burghardt, Rolf Senczuk, Frank Simon and Michael Field at Microlas/Lambda Physik for their interest in our work and assistance in performing the excimer raster scans.

This work performed under the auspices of the U.S. Department of Energy by Lawrence Livermore National Laboratory under Contract No. W-7405-ENG-48.

\section{REFERENCES}

1. M. Runkel, M. Yan, J. DeYoreo, N. Zaitseva, "The effect of impurities and stress on the damage distributions of rapidly grown KDP crystals," Laser-induced Damage in Optical Materials: 1997, SPIE Proceedings, Volume 3244, pp. 211-222, 1998

2. M. Yan, R. Torres, M. Runkel, B. Woods, I. Hutcheon, N. Zaitseva, and J. De Yoreo, "Impurity and laser-induced damage in the growth sectors of rapidly grown KDP crystals," Laser-induced Damage in Optical Materials: 1996, SPIE Proceedings Volume 2966, pp. 11-16, 1997

3. M. Runkel, S. Maricle, R. Torres, J. Auerbach, R. Floyd, R. Hawley-Fedder, A. Burnham, "The effect of thermal annealing and second harmonic generation on bulk damage performance of rapid-growth KDP Type I doublers at 1064 nm," Laser-induced Damage in Optical Materials: 2000, SPIE Proceedings, Volume 4347, pp. 389-399, 2001

4. A. Burnham, M. Runkel, R. Hawley-Fedder, M. Carman, R. Torres, P. Whitman, "Low-temperature growth of DKDP for improving laser-induced damage resistance at $350 \mathrm{~nm}$," Laser-induced Damage in Optical Materials: 2000, SPIE Proceedings, Volume 4347, pp. 373-381, 2001

5. M. Runkel, A. Burnham, D. Milam, W. Sell, M. Feit, A. Rubenchik, "The results of pulse scaling experiments on rapid-growth DKDP triplers using the Optical Sciences Laser at 351-nm," Laser-induced Damage in Optical Materials: 2000, SPIE Proceedings, Volume 4347, pp. 359-372, 2001

6. M. Feit, A. Rubenchik, M. Runkel, "Analysis of bulk DKDP damage distributions and pulse length dependence," Laser-induced Damage in Optical Materials: 2000, SPIE Proceedings, Volume 4347, pp. 383-389, 2001

7. L. J. Atherton, F. Rainer, J. J. De Yoreo, I. M. Thomas, N. Zaitseva, F. De Marco, "Thermal and laser conditioning of production- and rapid-growth KDP and KD*P crystals," Laser-Induced Damage in Optical Materials: 1993, SPIE Proceedings, Volume 2114, pp. 36-44, 1994

8. M. Runkel, J. DeYoreo, W. Sell, D. Milam, "Laser conditioning study of KDP on the Optical Sciences Laser using large area beams," Laser-Induced Damage in Optical Materials: 1997, SPIE Proceedings, Volume 3244, pages 51-63, 1998

9. M. Kozlowski, C. Wolfe, M. Staggs, J. Campbell, "Large-area laser conditioning of dielectric thin film mirrors, Laser induced Damage in Optical Materials: 1989, SPIE Proceedings, Volume 801, pp. 376-392, 1990

10. M. Runkel, "Monte Carlo simulation of the R/1 automated damage test," Laser induced Damage in Optical Materials: 1998, SPIE Proceedings, Volume 3578, 277-289, 1999

11. M. Runkel and R. Sharp, "Modeling KDP damage curves for the prediction of large area damage performance," Laserinduced Damage in Optical Materials: 1999, SPIE Proceedings, Volume 3902, pages 436-448, 2000

12. M. Feit, A. Rubenchik, M. Kozlowski, F. Genin, S. Schwartz, L. Sheehan, "Extrapolation of damage test data to predict performance of large-area NIF optics at $355 \mathrm{~nm}$," Laser-induced Damage in Optical Materials: 1998, SPIE Proceedings, Volume 3578, pp. 226-231, 1999

13. M. Runkel and A. Burnham, "Tripler vs. z-cut bulk damage in KDP and DKDP at $3 \omega$," Laser-induced Damage in Optical Materials: 2000, SPIE Proceedings, Volume 4347, pp. 408-419, 2001

14. H. Gong, Y. San, C. Li, "Effects of excimer laser irradiation on the KDP crystal," Laser-induced Damage in Optical Materials: 1998, SPIE Proceedings, Volume 3578, pp. 516-518, 1999

15. C. Marshall, J. Speth, L. DeLoach, S. Payne, "Penetrating radiation impact on NIF final optic components," Solid State Lasers for Application to Inertial Confinement Fusion: Second Annual International Conference, Paris, France, 2225 Oct. 1996, SPIE Proceedings, Volume 3047, pp. 1-21, 1996

16. A. Levchenko, V. Shul'ga, A. Doroshenko, "Impurity origin of the optical absorption and luminescence spectra of irradiated $\mathrm{KH}_{2} \mathrm{PO}_{4}$ crystals," Soviet Physics Solid State 32(8), pp. 1432-1433, 1990 


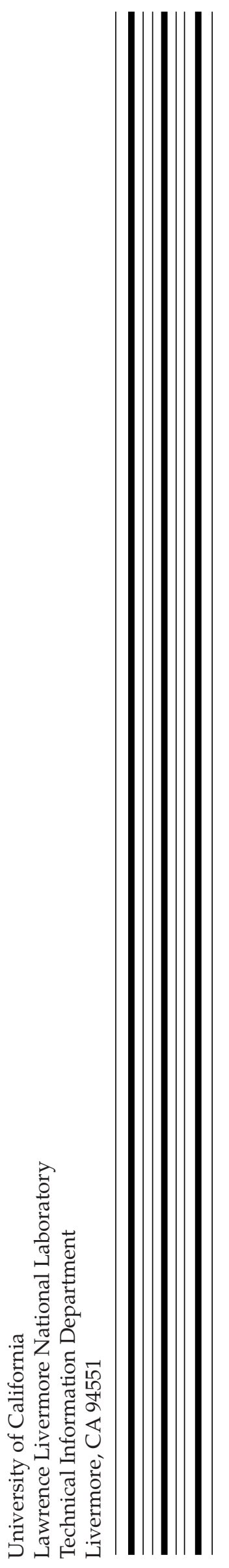

